Article

\title{
Facile Fabrication of Highly Active Magnetic Aminoclay Supported Palladium Nanoparticles for the Room Temperature Catalytic Reduction of Nitrophenol and Nitroanilines
}

\author{
Lei Jia ${ }^{1}$, Wensheng Zhang ${ }^{1}$, Jun Xu ${ }^{1, *}$, Jianliang Cao ${ }^{1}$ (i) , Zhouqing Xu ${ }^{1}$ (i) and Yan Wang ${ }^{2, *}$ (i) \\ 1 School of Chemistry and Chemical Engineering, Henan Polytechnic University, Jiaozuo 454000, China; \\ jlxj@hpu.edu.cn (L.J.); zhangwenshenghpu@163.com (W.Z.); caojianliang@hpu.edu.cn (J.C.); \\ zhqxu@hpu.edu.cn (Z.X.) \\ 2 School of Safety Science and Engineering, State Key Laboratory Cultivation Base for Gas Geology \\ and Gas Control, Henan Polytechnic University, Jiaozuo 454000, China \\ * Correspondence: xjj1@hpu.edu.cn (J.X.); yanwang@hpu.edu.cn (Y.W.); Tel.: +86-391-398-7816 (J.X.)
}

Received: 16 May 2018; Accepted: 4 June 2018; Published: 6 June 2018

\begin{abstract}
Magnetically recyclable nanocatalysts with excellent performance are urgent need in heterogeneous catalysis, due to their magnetic nature, which allows for convenient and efficient separation with the help of an external magnetic field. In this research, we developed a simple and rapid method to fabricate a magnetic aminoclay (AC) based an $\mathrm{AC}_{0} \mathrm{Fe}_{3} \mathrm{O}_{4} @ \mathrm{Pd}$ nanocatalyst by depositing palladium nanoparticles (Pd NPs) on the surface of the magnetic aminoclay nanocomposite. The microstructure and the magnetic properties of as-prepared $\mathrm{AC}_{\mathrm{C}} \mathrm{Fe} \mathrm{O}_{3} @ \mathrm{Pd}$ were tested using transmission electron microscopy (TEM), energy-dispersive X-ray spectroscopy (EDS), X-ray diffraction (XRD), and vibrating sample magnetometry (VSM) analyses. The resultant $\mathrm{AC} @ \mathrm{Fe}_{3} \mathrm{O}_{4} @ \mathrm{Pd}$ nanocatalyst with the magnetic Fe-based inner shell, catalytically activate the outer noble metal shell, which when combined with ultrafine Pd NPs, synergistically enhanced the catalytic activity and recyclability in organocatalysis. As the aminoclay displayed good water dispersibility, the nanocatalyst indicated satisfactory catalytic performance in the reaction of reducing nitrophenol and nitroanilines to the corresponding aminobenzene derivatives. Meanwhile, the $\mathrm{AC} @ \mathrm{Fe}_{3} \mathrm{O}_{4} @ \mathrm{Pd}$ nanocatalyst exhibited excellent reusability, while still maintaining good activity after several catalytic cycles.
\end{abstract}

Keywords: Pd nanoparticles; aminoclay; magnetic; 4-nitrophenol; nitrophenol and nitroanilines

\section{Introduction}

Recently, noble metal nanocatalysts have received much attention due to their high catalytic efficiency in many catalytic reactions including hydrogenation, dehydrogenation, oxidation, and so on [1-5]. However, noble metals are expensive and scarce resources, which severely limits their large-scale use. Therefore, it is important to increase the utilization rate of noble metals. The catalytic activity of the noble metal nanocatalyst is responsible for the catalytic reaction. It is reported that only the first layer of metal material responsible for the catalytic reaction. Therefore, in order to improve the specific surface area, it is necessary to synthesize metal nanoparticles that have small size and high dispersion [6]. However, as the diameter of the noble metal nanoparticles decreases, two problems arise: firstly, the surface energy gradually increases, which leads to the aggregation of the noble metal nanoparticles; secondly, the nanoparticles are difficult to separate from the reaction solution. These disadvantages generally result in reduced catalytic activity and reusability. In order to 
overcome the above drawbacks, loading nanoparticles onto a suitable carrier is a viable solution [1]. Therefore, noble metal catalysts were often loaded onto various solid supports such as silica [7,8], silicon nanowires [9,10], magnetic microspheres [11,12], carbon-based materials [13], or metal oxides [14-16]. Among the magnetic catalyst supports, $\mathrm{Fe}_{3} \mathrm{O}_{4}$ is an ideal carrier, which is easy to prepare and has a very active surface for adsorbing/immobilizing metals and ligands. It can not only prevent aggregation of metal nanoparticles, but also promote recirculation of nanocatalysts by magnetic separation [4,5].

Among various noble metal nanoparticles, Pd nanoparticles (Pd NPs) have extremely small size and high surface-to-volume ratios and have received great attention in the past decades $[6,16]$. Pd NPs have demonstrated outstanding effectiveness as catalysts for catalytic properties in different organic reactions on chemical and pharmaceutical industries, including hydrogenation and $\mathrm{C}-\mathrm{C}$ coupling reactions $[17,18]$. For example, Naghipour et al. [19] reported that $\mathrm{Fe}_{3} \mathrm{O}_{4} @ \mathrm{CS}-\mathrm{Schiff}$ based $\mathrm{Pd}$ nanocatalysts showed higher catalytic activity for Suzuki-Miyaura and Heck-Mizoroki C-C coupling reactions. Molga et al. [20] reported a palladium on alumina catalyst as being a highly selective homogeneous catalyst for the reduction of 2,4-dinitrotoluene.

Since the organo-functionalized clays were first described in 1997 [12], layered clay materials that can be synthesized to tune their surface-charge properties have recently emerged as promising scaffolds for constructing functional materials [21]. As a representative, aminoclay (AC) is a layered clay of organic magnesium silicate, which shows excellent water-solubility as it can be self-exfoliated in water under electrostatic repulsive forces generated from protonated amino-groups [21,22]. Meanwhile, aminoclay is the most representative of the layered clays, its $\mathrm{R}$ group is $-\left(\mathrm{CH}_{2}\right)_{3} \mathrm{NH}_{2}$ and relative molecular mass is 1156 [23], and the distance between the centers of two parallel lamellae is about $1.7 \mathrm{~nm}$. Due to the good water-soluble of amino-clay, the noble metal nanoparticles supported on the surface can be brought into complete contact with the reactants to accelerate the reaction rate.

Based on the above consideration, we synthesized a facile, low-cost, and efficient catalyst $\mathrm{AC} @ \mathrm{Fe}_{3} \mathrm{O}_{4} @ \mathrm{Pd}$, with Pd NPs immobilized on the surface of magnetic aminoclay@Fe $\mathrm{O}_{4}\left(\mathrm{AC} @ \mathrm{Fe}_{3} \mathrm{O}_{4}\right)$. There was no material loss during the entire synthesis and the yield of the final nanocatalyst was high. $\mathrm{AC} @ \mathrm{Fe}_{3} \mathrm{O}_{4}$ was prepared through the sol-gel process and solvothermal method. And then, Pd NPs were fabricated on the surface of $\mathrm{AC@Fe} \mathrm{O}_{4}$ through $\mathrm{Pd}\left(\mathrm{NO}_{3}\right)_{2}$ followed by sodium borohydride $\left(\mathrm{NaBH}_{4}\right)$ reduction in water at room temperature. The AC provides a large surface area on which the Pd NPs were finely dispersed. The $\mathrm{AC} @ \mathrm{Fe}_{3} \mathrm{O}_{4} @ P d$ exhibited high catalytic efficiency for the reduction of 4-nitrophenol (4-NP) and various nitroanilines by sodium borohydride. Compared with the aminoclay-metal nanocomposites in the literature $[21,24,25]$, the catalyst we prepared not only has good water dispersibility, but also has magnetic properties. Although the non-magnetic aminoclay-metal complex also has certain catalytic activity [26-28], it is difficult to achieve rapid separation of the catalyst from the substrate because of its excellent water solubility after the reaction is completed, which affects the efficiency of recycling. Furthermore, the catalyst could be easily separated from reaction solution by applying external magnetic fields for several cycles with good recycling stability in reaction mixture.

\section{Results and Discussion}

\subsection{Characterization of $\mathrm{AC@Fe} \mathrm{O}_{4} @ \mathrm{Pd}$}

The crystalline structure of the as-obtained sample was investigated by XRD analysis. Figure 1 displays the XRD patterns of $\mathrm{AC}, \mathrm{AC} @ \mathrm{Fe}_{3} \mathrm{O}_{4}$, and $\mathrm{AC} @ \mathrm{Fe}_{3} \mathrm{O}_{4} @ \mathrm{Pd}$. The original aminoclay (AC) exhibits four peaks centered at $2 \theta=22.9^{\circ}, 34.8^{\circ}$, and $59.6^{\circ}$, which was in agreement with the literatures [21]. The diffraction patterns for the magnetic $\mathrm{AC} @ \mathrm{Fe}_{3} \mathrm{O}_{4}$ displayed six characteristic peaks at $30.2^{\circ}, 35.5^{\circ}, 43.1^{\circ}$, $53.4^{\circ}, 57.1^{\circ}$, and $62.8^{\circ}$, corresponding to the (220), (311), (400), (422), (511), and (440) planes of the face centered cubic (fcc) structures of the $\mathrm{Fe}_{3} \mathrm{O}_{4}$ nanoparticles (JCPDS No. 75-1609), respectively. While after loading the $\mathrm{Pd}$ nanoparticles, the XRD pattern of the $\mathrm{AC} @ \mathrm{Fe}_{3} \mathrm{O}_{4} @ \mathrm{Pd}$ presented almost the same feature as those shown in $\mathrm{AC} @ \mathrm{Fe}_{3} \mathrm{O}_{4}$, besides a broad peak at $2 \theta=40.1^{\circ}$, which corresponded to the amorphous 
peak of $\mathrm{Pd}(111)$ diffractions in $\mathrm{Pd} f c c$ crystals. This clearly demonstrated that the well-crystallized Pd NPs were loaded on the surface of magnetic $\mathrm{AC} @ \mathrm{Fe}_{3} \mathrm{O}_{4}$.

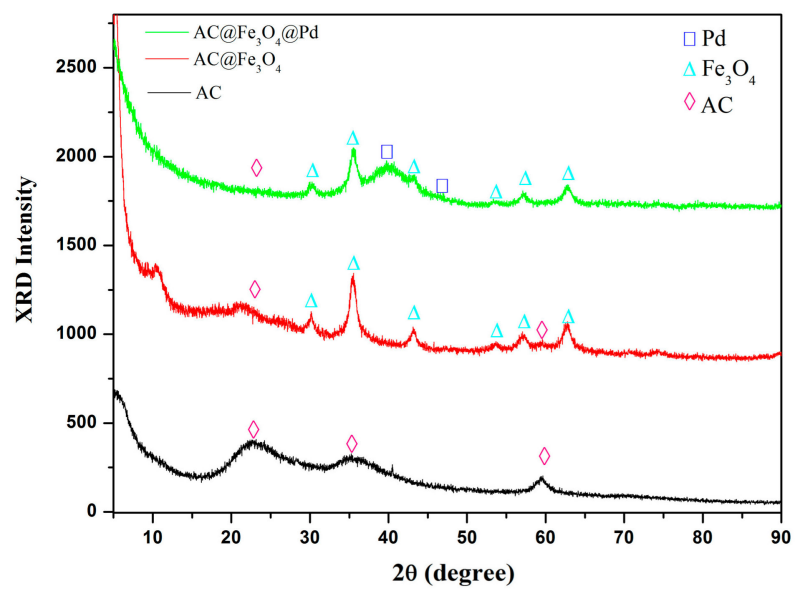

Figure 1. XRD patterns of $\mathrm{AC}, \mathrm{AC} @ \mathrm{Fe}_{3} \mathrm{O}_{4}$ and $\mathrm{AC} @ \mathrm{Fe}_{3} \mathrm{O}_{4} @ \mathrm{Pd}$.

For the prepared Mg-aminoclay, it indicated excellent water-soluble ability by delaminated clay sheets, which is associated with protonated amine $\left(-\mathrm{NH}_{3}{ }^{+}\right)$formation with a high density. Figure 2 shows the transmission electron microscopy (TEM) images of the magnetic AC@ $\mathrm{Fe}_{3} \mathrm{O}_{4}$ and $\mathrm{AC} @ \mathrm{Fe}_{3} \mathrm{O}_{4} @ \mathrm{Pd}$, which indicated that the aminoclay still maintained the sheet-like morphology, which was according to the previously reported microphotographs [29-31]. What was different from the original aminoclay was that, there were some more uniformly distributed $\mathrm{Fe}_{3} \mathrm{O}_{4}$ nanoparticles on the surface of the sheet-like structure, which formed a core-shell nanocomposite (Figure 2a,b) and lain the foundation of the catalyst reuse through the simple magnetic separation. Finally, a layer of $\mathrm{Pd}$ nanoparticles on the above $\mathrm{AC} @ \mathrm{Fe}_{3} \mathrm{O}_{4}$ catalyst carrier was fabricated by the classical reduction method, as shown in Figure 2c,d.

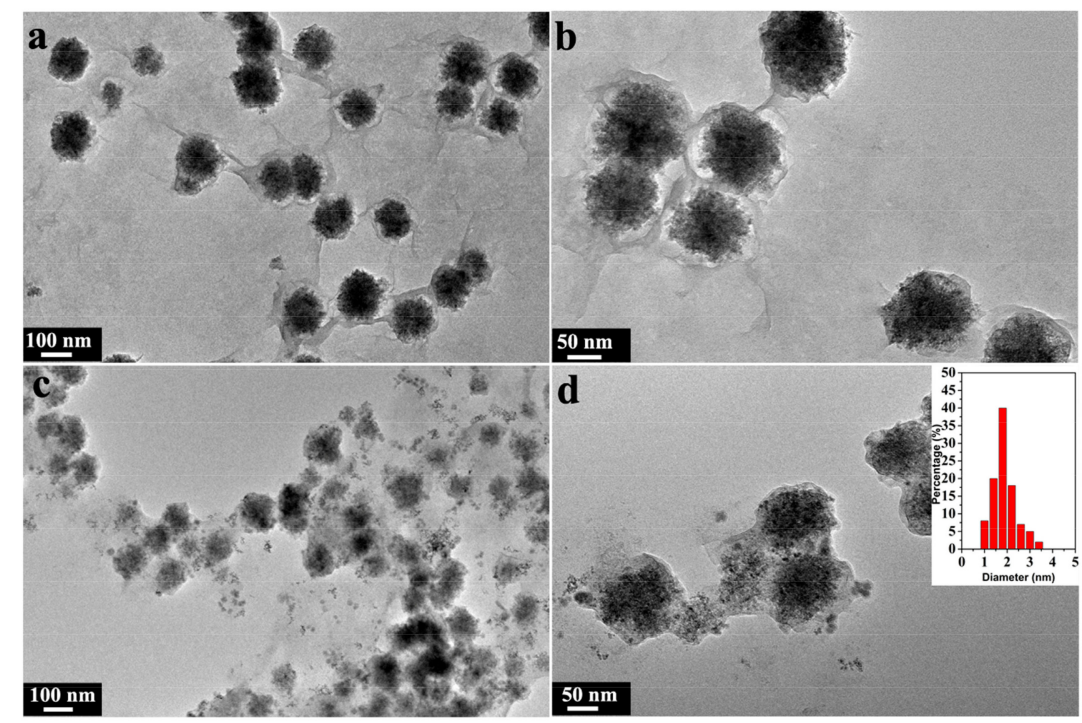

Figure 2. The TEM images of the magnetic $\mathrm{AC} @ \mathrm{Fe}_{3} \mathrm{O}_{4}$ catalyst carrier $(\mathbf{a}, \mathbf{b})$ and the final $\mathrm{AC}_{\mathrm{CFe}} \mathrm{O}_{4} @ \mathrm{Pd}$ catalysts $(\mathbf{c}, \mathbf{d})$.

The chemical composition and elemental distribution of $\mathrm{AC} @ \mathrm{Fe}_{3} \mathrm{O}_{4} @ \mathrm{Pd}$ were investigated by EDX-mapping and the energy-dispersive X-ray spectroscopy (EDX). Clearly form Figure 3, N, Si, 
$\mathrm{Mg}, \mathrm{Fe}$, and Pd elements were distributed on $\mathrm{AC} @ \mathrm{Fe}_{3} \mathrm{O}_{4} @ \mathrm{Pd}$. The zone of the distribution of N, Si, and $\mathrm{Mg}$ elements was larger than that of $\mathrm{Pd}$ and $\mathrm{Fe}$, which was consistent with the result that core-shell structure of the $\mathrm{AC} @ \mathrm{Fe}_{3} \mathrm{O}_{4} @ \mathrm{Pd}$ was formed. The dark-field images indicated abundant deposition of $\mathrm{Pd}$ nanoparticles on the magnetic carrier. Meanwhile, these results also indicated that the $\mathrm{Pd}$ elements were evenly dispersed among the magnetic carrier. The EDX spectrum of the $\mathrm{AC} @ \mathrm{Fe}_{3} \mathrm{O}_{4} @ \mathrm{Pd}$ (Figure 4a) exhibited the presence of N, Si, Mg, Fe, and Pd elements, which also proved the successful deposition of Pd on the $\mathrm{AC} @ \mathrm{Fe}_{3} \mathrm{O}_{4}$ catalysts carrier. ICP-AES was used to determine the Pd content (about 3.6 wt \%) on fresh $\mathrm{AC} @ \mathrm{Fe}_{3} \mathrm{O}_{4} @ \mathrm{Pd}$, which was consistent with the designed ratio.
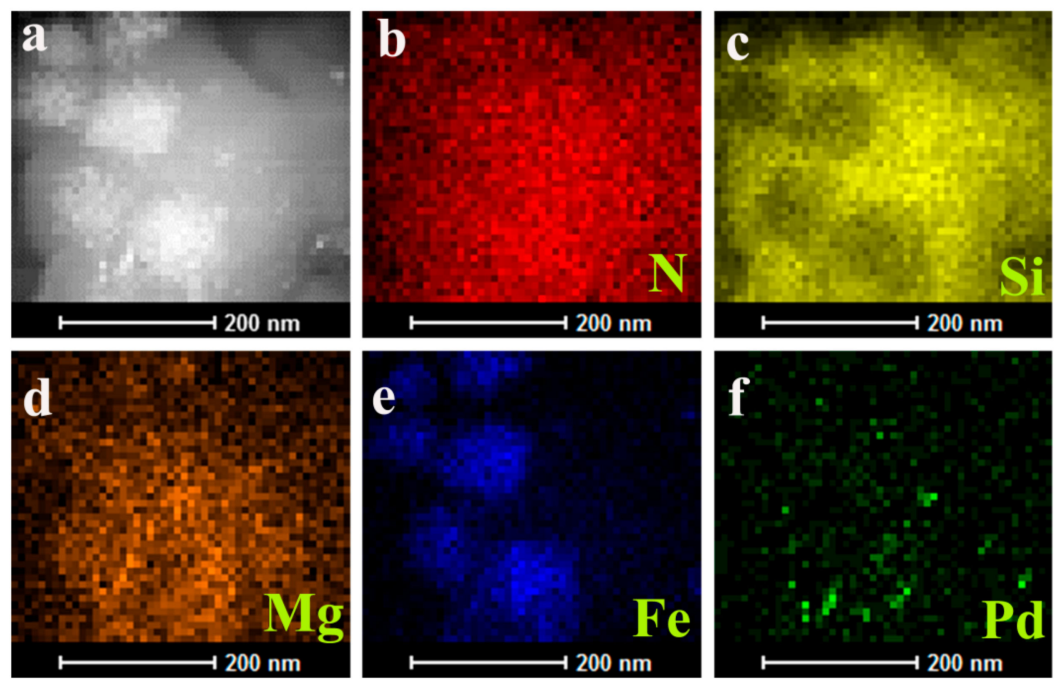

Figure 3. High angle annular dark-field scanning transmission electron microscopy (HAADF-STEM)

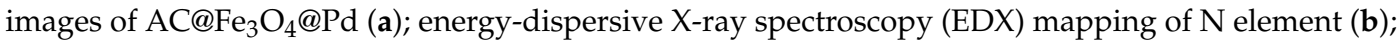
Si element (c); Mg element (d); Fe element (e) and Pd element (f).
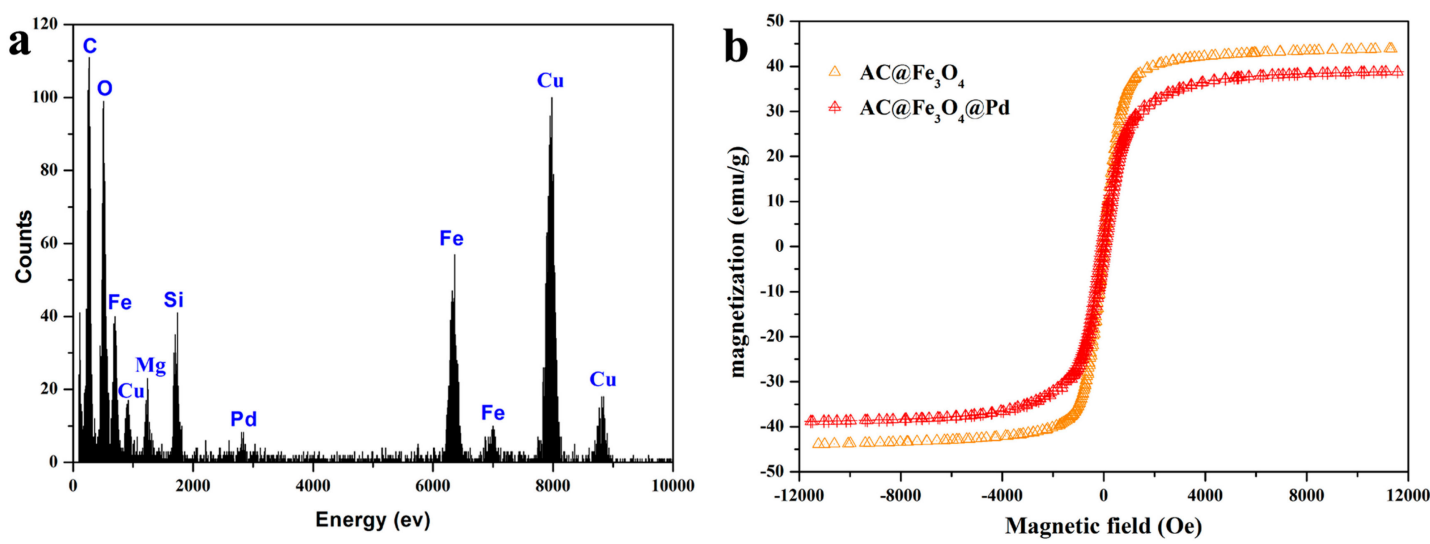

Figure 4. (a) EDX spectrum of $\mathrm{AC}_{\mathrm{F}} \mathrm{Fe}_{3} \mathrm{O}_{4} @ \mathrm{Pd}$ nanocatalysts. (b) Room-temperature magnetization hysteresis loops of the as-prepared $\mathrm{AC} @ \mathrm{Fe}_{3} \mathrm{O}_{4}$ and $\mathrm{AC} @ \mathrm{Fe}_{3} \mathrm{O}_{4} @ \mathrm{Pd}$.

The magnetic properties of the as-prepared $\mathrm{AC} @ \mathrm{Fe}_{3} \mathrm{O}_{4} @ \mathrm{Pd}$ nanocatalyst and the original catalyst carrier were investigated. Figure $4 \mathrm{~b}$ shows the $\mathrm{M}-\mathrm{H}$ hysteresis loops of the $\mathrm{AC}_{\mathrm{CFe}} \mathrm{O}_{4}$ and $\mathrm{AC} @ \mathrm{Fe}_{3} \mathrm{O}_{4} @ \mathrm{Pd}$ measured by sweeping the external field between -1.2 and $1.2 \mathrm{~T}$ at room temperature. There were no remanence and coercivity on the two magnetization curves, which suggested the $\mathrm{AC} @ \mathrm{Fe}_{3} \mathrm{O}_{4} @ \mathrm{Pd}$ nanocatalyst still maintained the superparamagnetic behavior after the surface modification. The magnetization value of $\mathrm{AC} @ \mathrm{Fe}_{3} \mathrm{O}_{4} @ \mathrm{Pd}\left(39.2 \mathrm{emu} \mathrm{g}{ }^{-1}\right)$ was lower than $\mathrm{AC}_{0} @ \mathrm{Fe}_{3} \mathrm{O}_{4}$ (44.6 emu $\mathrm{g}^{-1}$ ), which can be due to the loading of non-magnetic Pd nanoparticles. However, the magnetic sensitivity of the as-prepared $\mathrm{AC} @ \mathrm{Fe}_{3} \mathrm{O}_{4} @ \mathrm{Pd}$ was strong enough to achieve magnetic 
separation of the nanocatalyst after the catalytic reaction. All the above results reveal that the recyclable magnetic $\mathrm{AC} @ \mathrm{Fe}_{3} \mathrm{O}_{4} @ \mathrm{Pd}$ nanocatalyst had been successfully fabricated.

\subsection{Catalytic Activity}

The reduction of 4-nitrophenol to 4-aminophenol under the action of excess sodium borohydride $\left(\mathrm{NaBH}_{4}\right)$ was carried out to evaluate the catalytic performance of $\mathrm{AC} @ \mathrm{Fe}_{3} \mathrm{O}_{4} @ \mathrm{Pd}$ nanocatalyst. To start with, 4-NP was added into deionized water; after sonication for about $15 \mathrm{~min}$, the color of solution was light yellow and the UV-vis spectrum showed an absorption peak centered at $318 \mathrm{~nm}$. After the addition of excess $\mathrm{NaBH}_{4}(1.2 \mathrm{M}, 0.25 \mathrm{~mL})$, the color of the above mixed solution changed from light yellow to dark yellow and the UV-vis absorption spectrum of the 4-nitrophenolate salt exhibited a characteristic peak produced by the nitro compound at about $400 \mathrm{~nm}$ (Figure 5a) [32,33].
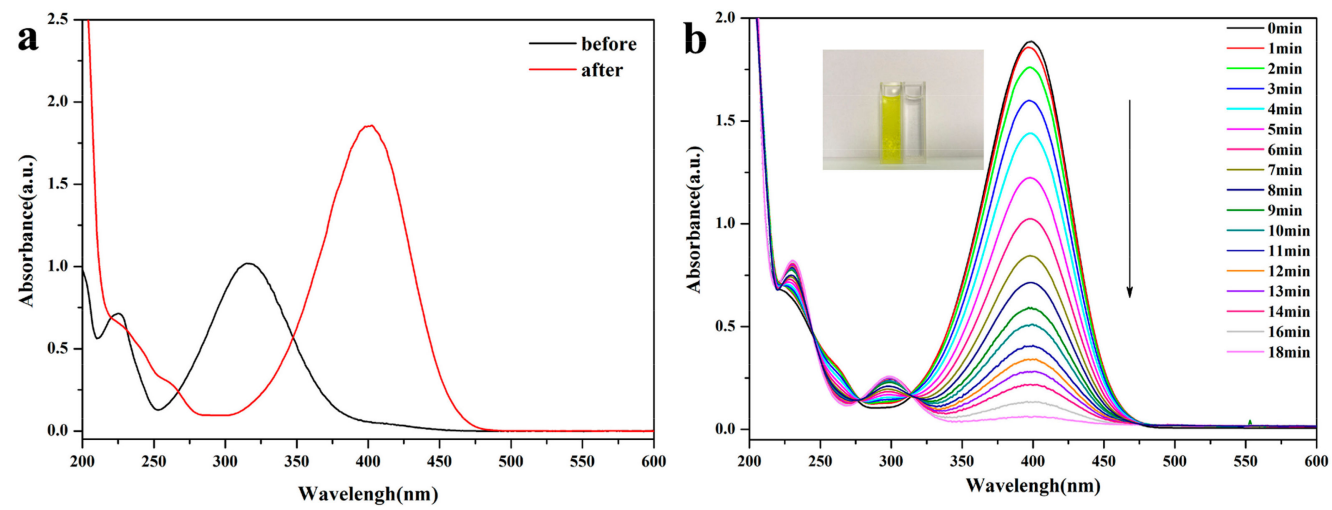

Figure 5. (a) UV-vis spectra of 4-NP before and after adding $\mathrm{NaBH}_{4}$ solution. (b) Absorption spectra observed at different reaction time indicating the decrease in the absorbance intensity at $400 \mathrm{~nm}$ and the appearance of a new band at $233 \mathrm{~nm}$ and $300 \mathrm{~nm}$.

In the absence of $\mathrm{AC} @ \mathrm{Fe}_{3} \mathrm{O}_{4} @ \mathrm{Pd}$, there was only a small amount of bubbles without the addition of as-prepared nanocatalyst, due to the slow hydrogen generation between $\mathrm{NaBH}_{4}$ and water molecules [34]. However, in the presence of this noble metal nanocatalyst, a large amount of bubbles appeared along with the gradual fading of the bright yellow solution. As shown in Figure $5 b$, the color of the above mixed solution was restored to the original colorless within $18 \mathrm{~min}$, demonstrating the completion of this catalytic reaction. The intensity of the characteristic absorption peak of 4-NP from UV-vis spectrum at $400 \mathrm{~nm}$ quickly weakened until it disappeared within $18 \mathrm{~min}$ along with the appearance of two new adsorption peaks at about 233 and $300 \mathrm{~nm}$, suggesting that all of the 4-NP were reduced to 4-AP [35,36].

In addition, we also investigated the catalytic properties of $\mathrm{AC} @ \mathrm{Fe}_{3} \mathrm{O}_{4} @ \mathrm{Pd}$ on the reduction of other nitroanilines such as o-Nitroaniline, $\mathrm{m}$-nitroaniline, p-nitroaniline, and 2,4-nitroaniline. All the catalytic conditions of the above nitroanilines were the same as that of 4-NP and the reaction progresses of these derivatives were monitored by UV-vis spectrometry. As shown in Table 1, the reduction time of each substrate and the conversion were calculated, which indicate that the $\mathrm{AC}_{0} \mathrm{Fe}_{3} \mathrm{O}_{4} @ \mathrm{Pd}$ displayed good catalytic performance with satisfactory yield toward nitrophenol and nitroaniline derivatives regardless of different substituent groups. From Figure 6a-d we can also observe that the highest characteristic absorption peak of each substituent gradually weakened within 9-23 min, which proved the excellent percent conversion of the prepared noble metal nanocatalyst. 
Table 1. Reduction of various nitrophenol and nitroanilines using $\mathrm{AC}_{\mathrm{CFe}} \mathrm{O}_{4} @ \mathrm{Pd}$ (Reaction condition: $0.25 \mathrm{~mL}$ of $3.4 \times 10^{-3} \mathrm{M}$ substrates and $0.25 \mathrm{~mL}$ of $1.2 \mathrm{M}$ fresh $\mathrm{NaBH}_{4}$ at the room temperature; the amount of catalysts dosage is $14 \mu \mathrm{g}$ in every reaction and the conversion is more than $98 \%$ ).

\begin{tabular}{ccc}
\hline Compound & Time/min & Rate Constant/min \\
\hline p-Nitroaniline & 21 & 0.124 \\
m-Nitroaniline & 14 & 0.235 \\
o-Nitroaniline & 9 & 0.407 \\
2,4-Nitroaniline & 23 & 0.119 \\
p-Nitrolpenol & 18 & 0.171 \\
\hline
\end{tabular}
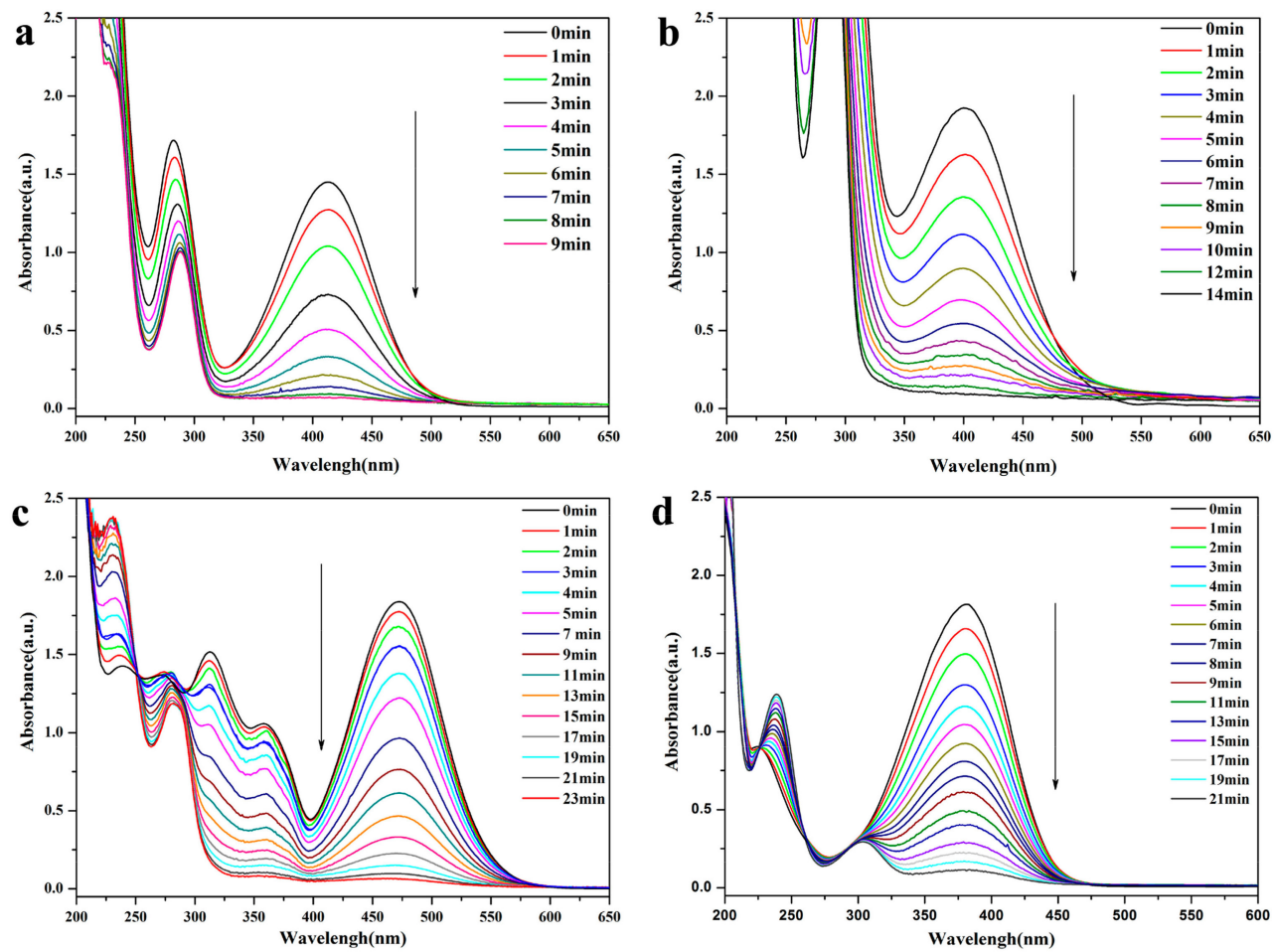

Figure 6. UV-Vis absorption spectra for the reduction of (a) o-Nitroaniline; (b) m-nitroaniline (c) 2,4-nitroaniline; (d) p-nitroaniline using $\mathrm{AC} @ \mathrm{Fe}_{3} \mathrm{O}_{4} @ \mathrm{Pd}$ nanocomposites.

Since the concentration of $\mathrm{NaBH}_{4}$ in the reaction was much higher than the 4-NP concentration, this eliminated the effect of donor $\mathrm{BH}_{4}{ }^{-}$on the catalytic reaction. This means that the reaction rate can be considered to depend only on the concentration of 4-NP. Thus, the rate of catalytic reaction was evaluated using pseudo-first-order kinetics, which is given as $k_{a p} t=\ln \left(C_{t} / C_{0}\right)$, where $C_{0}$ is the initial absorbance of the reagents at the maximum absorption wavelength, $C_{t}$ is the absorbance of reagents at maximum absorption wavelength under different time $t$, and $K_{a p}$ is the apparent rate constant. In order to quantitatively describe the reaction kinetics, the graphs and reaction times of $\ln \left(C_{t} / C_{0}\right)$ are shown in Figure $7 \mathrm{a}$. The reaction rate constant $K_{a p}$ can be calculated from the slope of the linear fit in the Figure 7a, which refers to the rate of degradation of the 4-nitrophenol concentration. The rate constant of our synthesized catalyst was $0.171 \mathrm{~min}^{-1}$. It is well known that the rate constant is influenced by many factors, such as metal nanoparticle loading, the usage of $\mathrm{NaBH}_{4}$, and catalysts. Table 2 lists some $\mathrm{k}$ values and experimental parameters in recent studies. Taking a small usage of catalysts $(14 \mu \mathrm{g})$ and high k/m $\mathrm{Pd}$ value into account, the catalytic performance of $\mathrm{AC} @ \mathrm{Fe}_{3} \mathrm{O}_{4} @ \mathrm{Pd}$ nanocatalyst was superior than other catalysts based on Pd nanoparticles [37-40]. Besides the $\mathrm{k}$ value, the TOF was also calculated and the value was about $0.928 \mathrm{~s}^{-1}$. Compared with recent studies with 
catalysts based on Pd nanoparticles, the TOF value of $\mathrm{AC} @ \mathrm{Fe}_{3} \mathrm{O}_{4} @ \mathrm{Pd}$ nanocatalyst was also higher than others $[36,41,42]$.
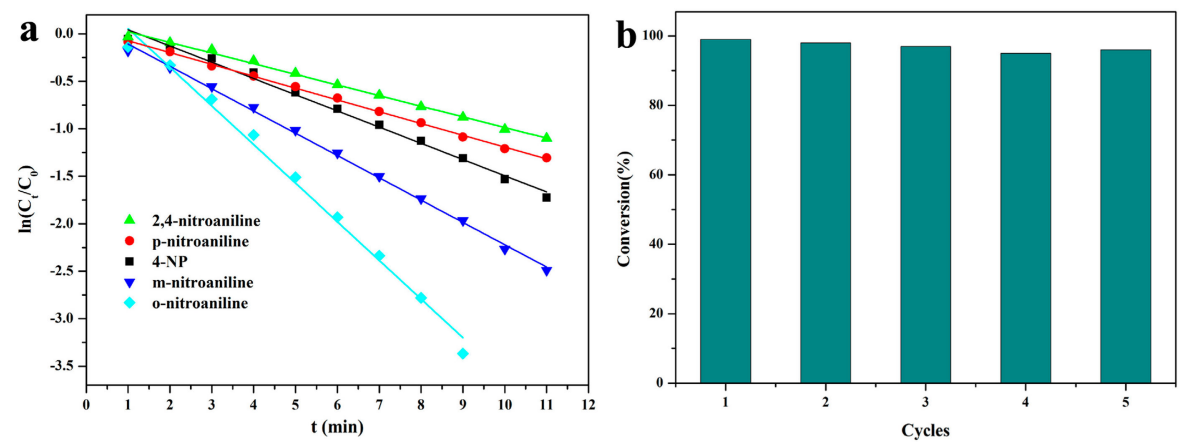

Figure 7. (a) Plot of $\ln \left(\mathrm{C}_{\mathrm{t}} / \mathrm{C}_{0}\right)$ against time for the reduction of 2,4-nitroaniline (green), p-nitroaniline (red), 4-NP (black), m-nitroaniline (blue), o-Nitroaniline (light green). (b) Conversion of 4-NP in successive cycles with $\mathrm{AC} @ \mathrm{Fe}_{3} \mathrm{O}_{4} @ \mathrm{Pd}$.

Table 2. Comparison of $\mathrm{k}$ for the reduction of 4-NP in different catalytic systems.

\begin{tabular}{|c|c|c|c|c|c|c|}
\hline Catalysts & $\begin{array}{c}\text { Catalysts } \\
\text { Dosage (mg) }\end{array}$ & $\begin{array}{l}\text { Pd Loading } \\
\text { (wt \%) }\end{array}$ & $\mathrm{NaBH}_{4}$ Dosage & $\begin{array}{l}\text { K Value } \\
\left(\min ^{-1}\right)\end{array}$ & $\begin{array}{c}\mathrm{K} / \mathrm{m}_{\mathrm{Pd}} \text { Value } \\
\left(\mathrm{min}^{-1} \mathrm{mg}^{-1}\right)^{\mathrm{a}}\end{array}$ & References \\
\hline $\begin{array}{c}\text { Mesoporous Pd } \\
\text { leaves }\end{array}$ & 0.25 & Nearly 100 & $0.3 \mathrm{~mL} \times 0.1 \mathrm{M}$ & 0.49 & 1.96 & 38 \\
\hline $\mathrm{Pd} / \mathrm{rGS}$ & 0.5 & 7.5 & $1.0 \mathrm{~mL} \times 0.1 \mathrm{M}$ & 0.27 & 7.2 & 40 \\
\hline $\mathrm{Fe}_{\mathrm{x}} \mathrm{O}_{\mathrm{y}} / \mathrm{Pd} @ \mathrm{mSiO}_{2}$ & 0.1 & 1.9 & $0.5 \mathrm{~mL} \times 0.26 \mathrm{M}$ & 0.096 & 50.53 & 41 \\
\hline $\mathrm{AC@} @ \mathrm{Fe}_{3} \mathrm{O}_{4} @ \mathrm{Pd}$ & 0.014 & 3.6 & $0.08 \times 1.2 \mathrm{M}$ & 0.171 & 339.29 & Here \\
\hline
\end{tabular}

a The value of $\mathrm{k} / \mathrm{m}_{\mathrm{Pd}}$ was calculated based on the $\mathrm{k}$ value and mass of Pd nanoparticles in corresponding catalysts.

In addition, the recyclability of a catalyst was very important for the heterogeneous catalytic process [43]. The as-prepared $\mathrm{AC} @ \mathrm{Fe}_{3} \mathrm{O}_{4} @ \mathrm{Pd}$ nanocatalyst could be easily separated from the solution by using an external magnet, due to its magnetic property. To test the recyclability of the catalysts, five cyclic reactions of the catalyst $\mathrm{AC}_{0} \mathrm{Fe}_{3} \mathrm{O}_{4} @ \mathrm{Pd}$ were evaluated. After the hydrogenation of 4-NP was repeated each time, the nanocatalyst was washed and dried and directly used for the next catalysis. As revealed in Figure $7 \mathrm{~b}$, with the increase of the number of cycles, the conversion rate slightly fluctuated but little changed, demonstrating the $\mathrm{AC}_{\mathrm{CFe}} \mathrm{O}_{4} @ \mathrm{Pd}$ nanocatalyst did not lose its initial catalytic activity and still showed good stability and catalytic activity.

\section{Materials and Methods}

\subsection{Chemicals}

Magnesium chloride hexahydrate $\left(\mathrm{MgCl}_{2} \cdot 6 \mathrm{H}_{2} \mathrm{O}\right)$, 3-Aminopropyltriethoxysilane (APTES), ferric chloride hexahydrate $\left(\mathrm{FeCl}_{3} \cdot 6 \mathrm{H}_{2} \mathrm{O}\right)$, ethylene glycol, sodium acetate anhydrous, polyethylene imine, palladium nitrate $\left(\mathrm{Pd}\left(\mathrm{NO}_{3}\right)_{2}\right)$, o-Nitroaniline (o-NA), m-nitroaniline, p-nitroaniline, 4-nitrophenol(4-NP), 2,4-nitroaniline, and sodium borohydride $\left(\mathrm{NaBH}_{4}\right)$ were purchased from Sigma-Aldrich Chemical Co. All the chemicals and solvents are reagent grade and received without any further purification. Ultrapure water was prepared by using NANO Pure Infinity System (Barnstead/Thermolyne Corp., Dubuque, Iowa, USA) and was used throughout all the experimental processes.

\subsection{Preparation of Aminoclay (AC)}

$\mathrm{AC}$ was prepared by the method according to the previous report [44]: The $\mathrm{MgCl}_{2} \cdot 6 \mathrm{H}_{2} \mathrm{O}(1.68 \mathrm{~g}$, $8.3 \mathrm{mmol}$ ) was dissolved into $50 \mathrm{~mL}$ of absolute ethanol under ultrasonic dispersion, APTES (1.68 $\mathrm{g}$, 
$8.3 \mathrm{mmol}$ ) was dropwise added and the solution was stirred at room temperature for $24 \mathrm{~h}$. The light-yellow solid was collected by centrifugation and washed with absolute ethanol for three times. Finally, the obtained solid was dried under vacuum at $80{ }^{\circ} \mathrm{C}$ for $6 \mathrm{~h}$.

\subsection{Preparation of $\mathrm{AC} @ \mathrm{Fe}_{3} \mathrm{O}_{4}$ Composites}

The $\mathrm{AC} @ \mathrm{Fe}_{3} \mathrm{O}_{4}$ composites were prepared by the method of solvothermal reaction: One gram $\mathrm{FeCl}_{3} 6 \mathrm{H}_{2} \mathrm{O}$ was dissolved in $30 \mathrm{~mL}$ of ethylene glycol to form a clear yellow solution after adding $2.7 \mathrm{~g}$ sodium acetate anhydrous and $0.75 \mathrm{~g}$ polyethylene imine, the mixed solution was stirred for $30 \mathrm{~min}$. $0.3 \mathrm{~g}$ of AC powder was added into the above solution and were fully ultrasound for $3 \mathrm{~h}$. The mixed solution was then poured into a teflon-lined stainless-steel autoclave and reacted at $200{ }^{\circ} \mathrm{C}$ for $8 \mathrm{~h}$. After the reaction was completed, the solution was cooled to room temperature and the product was collected with the help of a magnet file. The products were washed with ethanol and deionized water for several times and dried under vacuum at $50{ }^{\circ} \mathrm{C}$ for $3 \mathrm{~h}$ for further use.

\subsection{Preparation of $A C @ F e_{3} \mathrm{O}_{4} @ P d$ Composites}

The $\mathrm{AC} @ \mathrm{Fe}_{3} \mathrm{O}_{4} @ \mathrm{Pd}$ were prepared by the method of conventional impregnation and subsequent reduction steps: $\mathrm{Pd}\left(\mathrm{NO}_{3}\right)_{2}(12 \mathrm{mg}, 46.3 \mathrm{~mol} \mathrm{Pd})$ and $\mathrm{AC} @ \mathrm{Fe}_{3} \mathrm{O}_{4}(140 \mathrm{mg})$ were dispersed in $15 \mathrm{~mL}$ aqueous solution and the mixture was stirred for $3 \mathrm{~h}$ at room temprature. Subsequently, $1.0 \mathrm{~mL} \mathrm{NaBH}_{4}$ (56 mg, $1.4 \mathrm{mmol}$ ) aqueous solution was added to the above solution and the solution was stirred for $1 \mathrm{~h}$ under room temperature. Finally, the as-obtained $\mathrm{AC} @ \mathrm{Fe}_{3} \mathrm{O}_{4} @ \mathrm{Pd}$ composites were separated and collected with a magnet, followed by washing with deionized water three times, and drying under vacuum at $50{ }^{\circ} \mathrm{C}$ for $3 \mathrm{~h}$.

\subsection{Characterizations}

Transmission electron microscopy (TEM), high resolution transmission electron microscopy (HRTEM), and the energy dispersive spectra (EDS) were determined using a Tecnai-G2-F30 (FEI, Eindhoven, The Netherlands) at acceleration voltages of $200 \mathrm{kV}$. X-ray diffraction (XRD) measurements were carried out on a X'pert PRO X-ray power diffractometer (PANalytical Co.X'pert PRO, Almelo, The Netherlands) using Cu Ka radiation of 1.5406 A (40 kV, 30 mA). Magnetization measurements were performed on a vibrating sample magnetometry (VSM, LAKESHORE-7304, Clark County, NV, USA) at room temperature. The UV measurement was finished on a Shimadzu UV-240 spectrophotometer (Shimadzu Corporation, Kyotp, Japan). Pd contents of the samples were determined by inductively coupled plasma-atomic emission spectroscopy (ICP-AES) using an IRIS Advantage ER/S spectrophotometer (ICPE-9800, Shimadzu Corporation, Japan).

\subsection{Catalytic Studies}

The catalytic property of the as-obtained $\mathrm{AC} @ \mathrm{Fe}_{3} \mathrm{O}_{4} @ \mathrm{Pd}$ for the reduction of nitrophenol and nitroanilines: In a typical reaction, amounts of $8 \mathrm{~mL}$ of deionized water was mixed with $0.25 \mathrm{~mL}$ $\left(3.4 \times 10^{-3} \mathrm{M}\right)$ of 4 -nitrophenol and $0.25 \mathrm{~mL}$ of $\mathrm{NaBH}_{4}(1.2 \mathrm{M})$. After forming a homogeneous dispersion, $3 \mathrm{~mL}$ of the above mixture was transferred into quartz cuvette in sequence. Immediately after adding $14 \mu \mathrm{L}$ of $1 \mathrm{mg} / \mathrm{mL} \mathrm{AC@Fe}_{3} \mathrm{O}_{4} @ \mathrm{Pd}$, it could be observed that the solution color changed gradually vanished as the reaction proceeded. The reaction progress was quickly measured by UV-vis spectroscopy in a scanning range of 200-600 nm under the speed of $1200 \mathrm{~nm} / \mathrm{min}$ (UV-240, Shimadzu Corporation, Japan). The yellow color of the solution gradually vanished, indicating the formation of 4-aminophenol. Following the similar procedures, $\mathrm{AC} @ \mathrm{Fe}_{3} \mathrm{O}_{4} @ \mathrm{Pd}$ was also used as catalyst for the reduction of other nitroanilines. In the recycling study, the $\mathrm{AC} @ \mathrm{Fe}_{3} \mathrm{O}_{4} @ \mathrm{Pd}$ nanocatalyst was separated from the solution by using magnet when the reduction reaction completely finished. After washing using water for three times, they were reused in the next reaction run. The procedure was repeated ten times. 


\section{Conclusions}

In conclusion, the magnetic recoverable $\mathrm{AC}_{\mathrm{C}} \mathrm{Fe}_{3} \mathrm{O}_{4} @ \mathrm{Pd}$ nanocatalyst was fabricated through a facile way. The good water-solubility of the original aminoclay makes the final catalyst fully dispersed in water, which greatly increased the contact chance between the catalyst and substrates. The catalytic ability of $\mathrm{AC@} \mathrm{Fe}_{3} \mathrm{O}_{4} @ \mathrm{Pd}$ was confirmed by the study of the reduction of nitrophenol and nitroanilines to the corresponding aminobenzenes, which indicated the $\mathrm{AC} @ \mathrm{Fe}_{3} \mathrm{O}_{4} @ \mathrm{Pd}$ had good catalytic performance with satisfactory yield toward nitrophenol and nitroanilines regardless of different substituent groups. Furthermore, the $\mathrm{AC} @ \mathrm{Fe}_{3} \mathrm{O}_{4} @ \mathrm{Pd}$ can be separated from reaction system conveniently with the help of an external magnetic field, which gave the reusability of the prepared nanocatalyst. The as-obtained $\mathrm{AC} @ \mathrm{Fe}_{3} \mathrm{O}_{4} @ \mathrm{Pd}$ nanocomposite may become an ideal recyclable catalyst for the reduction of other aromatic compounds owing to its stability, dispersibility, and efficient magnetism.

Author Contributions: L.J. conceived and designed the experiments; J.C., W.Z. and Z.X. performed the experiments and analyzed the data; J.X. and Y.W. provided the concept of this research and managed all the experimental and writing process as the corresponding authors; all authors discussed the results and commented on the manuscript.

Acknowledgments: This work was supported, in part, by the National Natural Science Foundation of China (51773052, 21404033, 21401046 and U1704146), the Science and Technology Research Project of Henan Province (162102210065 and 152102210314), the Science Research Funds for the Universities of Henan Province (NSFRF170305, NSFRF1607, NSFRF1606 and NSFRF170201), the Research Foundation for Youth Scholars of Higher Education of Henan Province (2016GGJS-040, 2017GGJS-053), Foundation for Distinguished Young Scientists of Henan Polytechnic University (J2016-2, J2017-3, J2018-2) and Program for Innovative Research Team of Henan Polytechnic University (T2018-2).

Conflicts of Interest: The authors declare no conflicts of interest.

\section{References}

1. Arrigo, R.; Wrabetz, S.; Schuster, M.E.; Wang, D.; Villa, A.; Rosenthal, D.; Girsgdies, F.; Weinberg, G.; Prati, L.; Schlögl, R.; et al. Tailoring the morphology of Pd nanoparticles on CNTs by nitrogen and oxygen functionalization. Phys. Chem. Chem. Phys. 2012, 14, 10523-10532. [CrossRef] [PubMed]

2. Guo, X.F.; Jang, D.Y.; Jang, H.G.; Kim, G.J. Hydrogenation and dehydrogenation reactions catalyzed by CNTs supported palladium catalysts. Catal. Today 2012, 186, 109-114. [CrossRef]

3. Weerachawanasak, P.; Mekasuwandumrong, O.; Arai, M.; Fujita, S.I.; Praserthdam, P.; Panpranot, J. Effect of strong metal-support interaction on the catalytic performance of $\mathrm{Pd} / \mathrm{TiO}_{2}$ in the liquid-phase semihydrogenation of phenylacetylene. J. Catal. 2009, 262, 199-205. [CrossRef]

4. Coker, V.S.; Bennett, J.A.; Telling, N.D.; Henkel, T.; Charnock, J.M.; van der Laan, G.; Pattrick, R.A.; Pearce, C.I.; Cutting, R.S.; Shannon, I.J.; et al. Microbial engineering of nanoheterostructures: Biological synthesis of a magnetically recoverable palladium nanocatalyst. ACS Nano 2010, 4, 2577-2584. [CrossRef] [PubMed]

5. Hong, Q.; Yu, S.; Yang, Y.; Liu, G.; Shao, Z. A polymorphism in JMJD2C alters the cleavage by caspase-3 and the prognosis of human breast cancer. Oncotarget 2014, 5, 4779-4787. [CrossRef] [PubMed]

6. Hyotanishi, M.; Isomura, Y.; Yamamoto, H.; Kawasaki, H.; Obora, Y. Surfactant-free synthesis of palladium nanoclusters for their use in catalytic cross-coupling reactions. Chem. Commun. 2011, 47, 5750-5752. [CrossRef] [PubMed]

7. Chen, Z.; Cui, Z.M.; Niu, F.; Jiang, L.; Song, W.G. Pd nanoparticles in silica hollow spheres with mesoporous walls: A nanoreactor with extremely high activity. Chem. Commun. 2010, 46, 6524-6526. [CrossRef] [PubMed]

8. Jia, L.; Zhou, T.; Xu, J.; Xu, Z.; Li, H.; Liu, B.; Sun, J.; Cao, J.; Shen, X.; Li, X. Synthesis and characterization of $\mathrm{PdRu}$ alloy-coated palygorskite-based nanocomposites as a magnetically recyclable multifunctional catalyst for reduction of nitroarenes and azo dyes. Mater. Lett. 2017, 197, 24-27. [CrossRef]

9. Yamada, Y.M.A.; Yuyama, Y.; Sato, T.; Fujikawa, S.; Uozumi, Y. A palladium-nanoparticle and silicon-nanowire-array hybrid: A platform for catalytic heterogeneous reactions. Angew. Chem. Int. Ed. 2014, 53, 127-131. [CrossRef] [PubMed] 
10. Yang, X.L.; Zhong, H.; Zhu, Y.H.; Jiang, H.L.; Shen, J.H.; Huang, J.F.; Li, C.Z. Highly efficient reusable catalyst based on silicon nanowire arrays decorated with copper nanoparticles. J. Mater. Chem. A 2014, 2, 9040-9047. [CrossRef]

11. Wang, C.; Salmon, L.; Ciganda, R.; Yate, L.; Moya, S.; Ruiz, J.; Astruc, D. An efficient parts-per-million a- $\mathrm{Fe}_{2} \mathrm{O}_{3}$ nanocluster/graphene oxide catalyst for Suzuki-Miyaura coupling reactions and 4-nitrophenol reduction in aqueous solution. Chem. Commun. 2017, 53, 644-646. [CrossRef] [PubMed]

12. Jia, L.; Zhou, T.; Xu, J.; Li, F.; Xu, Z.; Zhang, W.; Guo, S.; Shen, X.; Zhang, B. AuPd bimetallic nanocrystals embedded in magnetic halloysite nanotubes: Facile synthesis and catalytic reduction of nitroaromatic compounds. Nanomaterials 2017, 7, 333. [CrossRef] [PubMed]

13. Yan, Y.; Miao, J.; Yang, Z.; Xiao, F.X.; Yang, H.B.; Liu, B.; Yang, Y. Carbon nanotube catalysts: Recent advances in synthesis, characterization and applications. Chem. Soc. Rev. 2015, 44, 3295-3346. [CrossRef] [PubMed]

14. Cai, R.; Ellis, P.R.; Yin, J.; Liu, J.; Brown, C.M.; Griffin, R.; Chang, G.; Yang, D.; Ren, J.; Cooke, K.; et al. Performance of preformed $\mathrm{Au} / \mathrm{Cu}$ nanoclusters deposited on mgo powders in the catalytic reduction of 4-nitrophenol in solution. Small 2018, 14, 1703734. [CrossRef] [PubMed]

15. Bao, Z.; Yuan, Y.; Leng, C.; Li, L.; Zhao, K.; Sun, Z. One-pot synthesis of noble metal/zinc oxide composites with controllable morphology and high catalytic performance. ACS Appl. Mater. Interfaces 2017, 9, 16417-16425. [CrossRef] [PubMed]

16. Wang, C.Y.; Boucher, M.; Yang, M.; Saltsburg, H.; Flytzani-Stephanopoulos, M. ZnO-modified zirconia as gold catalyst support for the low-temperature methanol steam reforming reaction. Appl. Catal. B 2014, 154-155, 142-152. [CrossRef]

17. Wu, Y.; Wang, D.; Zhao, P.; Niu, Z.; Peng, Q.; Li, Y. Monodispersed Pd-Ni nanoparticles: Composition control synthesis and catalytic properties in the Miyaura-Suzuki reaction. Inorg. Chem. 2011, 50, 2046-2048. [CrossRef] [PubMed]

18. Bychkov, V.Y.; Tyulenin, Y.P.; Gorenberg, A.Y.; Sokolov, S.; Korchak, V. Evolution of Pd catalyst structure and activity during catalytic oxidation of methane and ethane. Appl. Catal. A Gen. 2014, 485, 1-9. [CrossRef]

19. Walker, A.; King, D. Production of synthesis gas by direct catalytic oxidation of methane on $\mathrm{Pt}\{110\}(1 \times 2)$ using supersonic molecular beams. J. Phys. Chem. B 2000, 104, 6462-6467. [CrossRef]

20. Naghipour, A.; Fakhri, A. Heterogeneous $\mathrm{Fe}_{3} \mathrm{O}_{4} @$ chitosan-Schiff base Pd nanocatalyst: Fabrication, characterization and application as highly efficient and magnetically-recoverable catalyst for Suzuki-Miyaura and Heck-Mizoroki C-C coupling reactions. Catal. Commun. 2016, 73, 39-45. [CrossRef]

21. Li, Q.F.; Jin, L.; Li, L.; Ma, W.; Wang, Z.; Hao, J. Water-soluble luminescent hybrid aminoclay grafted with lanthanide complexes synthesized by a Michael-like addition reaction and its gas sensing application in PVP nanofiber. J. Mater. Chem. C 2017, 5, 4670-4676. [CrossRef]

22. Zhao, L.Z.; Zhou, C.H.; Wang, J.; Tong, D.S.; Yu, W.H.; Wang, H. Recent advances in clay mineral-containing nanocomposite hydrogels. Soft Matter 2015, 11, 9229-9246. [CrossRef] [PubMed]

23. Assadi, A.A.; Bouzaza, A.; Lemasle, M.; Wolbert, D. Removal of trimethylamine and isovaleric acid from gas streams in a continuous flow surface discharge plasma reactor. Chem. Eng. Res. Des. 2015, 93, 640-651. [CrossRef]

24. Li, Q.F.; Liu, Z.; Jin, Z.; Yang, P.; Wang, Z. A water-soluble fluorescent hybrid material based on aminoclay and its bioimaging application. RSC Adv. 2017, 7, 44614-44618. [CrossRef]

25. Datta, K.K.R.; Achari, A.; Eswaramoorthy, M. Aminoclay: A functional layered material with multifaceted applications. J. Mater. Chem. A 2013, 1, 6707-6718. [CrossRef]

26. Hoseini, S.J.; Rashidi, M.; Bahrami, M. Platinum nanostructures at the liquid-liquid interface: Catalytic reduction of p-nitrophenol to p-aminophenol. J. Mater. Chem. 2011, 21, 16170-16176. [CrossRef]

27. Ravula, S.; Essner, J.B.; La, W.A.; Polo-Parada, L.; Kargupta, R.; Hull, G.J.; Sengupta, S.; Baker, G.A. Sunlight-assisted route to antimicrobial plasmonic aminoclay catalysts. Nanoscale 2015, 7, 86-91. [CrossRef] [PubMed]

28. Kumar, A.S.; Datta, K.K.R.; Rao, T.S.; Raghavan, K.V.; Eswaramoorthy, M.; Reddy, B.V.S. Pd-aminoclay nanocomposite as an efficient recyclable catalyst for hydrogenation and Suzuki cross coupling reactions. J. Nanosci. Nanotechnol. 2012, 12, 2000-2007. [CrossRef] [PubMed]

29. White, R.J.; Luque, R.; Budarin, V.L.; Clark, J.H.; Macquarrie, D.J. Supported metal nanoparticles on porous materials. Methods and applications. Chem. Soc. Rev. 2009, 38, 481-494. [CrossRef] [PubMed]

30. Lee, Y.C.; Park, W.K.; Yang, J.W. Removal of anionic metals by amino-organoclay for water treatment. J. Hazard. Mater. 2011, 190, 652-658. [CrossRef] [PubMed] 
31. Patil, A.J.; Mann, S. Self-assembly of bio-inorganic nanohybrids using organoclay building blocks. J. Mater. Chem. 2008, 18, 4605-4615. [CrossRef]

32. Wu, G.; Liang, X.; Zhang, L.; Tang, Z.; Almamun, M.; Zhao, H.; Su, X. Fabrication of highly stable metal oxide hollow nanospheres and their catalytic activity toward 4-nitrophenol reduction. ACS Appl. Mater. Interfaces 2017, 9, 18207-18214. [CrossRef] [PubMed]

33. Kim, T.; Fu, X.; Warther, D.; Sailor, M.J. Size-controlled Pd nanoparticle catalysts prepared by galvanic displacement into a porous Si-Iron oxide nanoparticle host. ACS Nano 2017, 11, 2773-2784. [CrossRef] [PubMed]

34. Wang, Z.; Su, R.; Wang, D.; Shi, J.; Wang, J.X.; Pu, Y.; Chen, J.F. Sulfurized graphene as efficient metal-free catalysts for reduction of 4-nitrophenol to 4-aminophenol. Ind. Eng. Chem. Res. 2017, 56, 13610-13617. [CrossRef]

35. Jin, Z.; Xiao, M.D.; Bao, Z.H.; Wang, P.; Wang, J.F. A general approach to mesoporous metal oxide microspheres loaded with noble metal nanoparticles. Angew. Chem. Int. Ed. 2012, 51, 6406-6410. [CrossRef] [PubMed]

36. Gu, X.M.; Qi, W.; Xu, X.Z.; Sun, Z.H.; Zhang, L.Y.; Liu, W.; Pan, X.L.; Su, D.S. Covalently functionalized carbon nanotube supported Pd nanoparticles for catalytic reduction of 4-nitrophenol. Nanoscale 2014, 6, 6609-6616. [CrossRef] [PubMed]

37. Dutta, S.; Sarkar, S.; Ray, C.; Roy, A.; Sahoo, R.; Pal, T. Mesoporous gold and palladium nanoleaves from liquid-liquid interface: Enhanced catalytic activity of the palladium analogue toward hydrazine-assisted room-temperature 4-nitrophenol reduction. ACS Appl. Mater. Interfaces 2014, 6, 9134-9143. [CrossRef] [PubMed]

38. Wang, Z.M.; Xu, C.L.; Gao, G.Q.; Li, X. Facile synthesis of well-dispersed Pd-graphene nanohybrids and their catalytic properties in 4-nitrophenol reduction. RSC Adv. 2014, 4, 13644-13651. [CrossRef]

39. Bramhaiah, K.; John, N.S. Hybrid films of reduced graphene oxide with noble metal nanoparticles generated at a liquid/liquid interface for applications in catalysis. RSC Adv. 2013, 3, 7765-7773. [CrossRef]

40. Yao, T.J.; Cui, T.Y.; Fang, X.; Cui, F.; Wu, J. Preparation of yolk-shell $\mathrm{Fe}_{\mathrm{x}} \mathrm{O}_{\mathrm{y}} / \mathrm{Pd} @$ mesoporous $\mathrm{SiO}_{2}$ composites with high stability and their application in catalytic reduction of 4-nitrophenol. Nanoscale 2013, 5, 5896-5904. [CrossRef] [PubMed]

41. Liu, J.; Huo, X.; Li, T.R.; Yang, Z.Y.; Xi, P.X.; Wang, Z.Y.; Wang, B.D. Palladium nanoparticles bonded to two-dimensional iron oxide graphene nanosheets: A synergistic and highly reusable catalyst for the Tsuji-Trost reaction in water and air. Chem. Eur. J. 2014, 20, 11549-11555. [CrossRef] [PubMed]

42. Chen, Z.; Cui, Z.M.; Li, P.; Cao, C.Y.; Hong, Y.L.; Wu, Z.Y.; Song, W.G. Diffusion induced reactant shape selectivity inside mesoporous pores of $\mathrm{Pd@meso-SiO} 2$ nanoreactor in Suzuki coupling reactions. J. Phys. Chem. C 2012, 116, 14986-14991. [CrossRef]

43. Sheng, J.; Wang, L.; Deng, L.; Zhang, M.; He, H.; Zeng, K.; Tang, F.; Liu, Y.N. MOF-templated fabrication of hollow $\mathrm{Co}_{4} \mathrm{~N} @ \mathrm{~N}$-doped carbon porous nanocages with superior catalytic activity. ACS Appl. Mater. Interfaces 2018, 10, 7191-7200. [CrossRef] [PubMed]

44. Lee, Y.C.; Lee, H.U.; Lee, K.; Kim, B.; Lee, S.Y.; Choi, M.H.; Farooq, W.; Choi, J.S.; Park, J.Y.; Lee, J.; et al. Aminoclay-conjugated $\mathrm{TiO}_{2}$ synthesis for simultaneous harvesting and wet-disruption of oleaginous Chlorella sp. Chem. Eng. J. 2014, 245, 143-149. [CrossRef]

(C) 2018 by the authors. Licensee MDPI, Basel, Switzerland. This article is an open access article distributed under the terms and conditions of the Creative Commons Attribution (CC BY) license (http:/ / creativecommons.org/licenses/by/4.0/). 